Article

\title{
The Deterioration of Ultrapure Water Quality Under the Influence of Hydrogen Peroxide
}

\author{
Toshikazu ABE, Arihiro NOMURA, Tooru AMAYA and Yoshitaka YAMAKI \\ Technical Planning Div., Nomura Micro Science Co., Ltd., 2-9-8, Okada, Atsugi, Kanagawa, 243-0021, \\ Japan \\ Tooru KUSANO, Hironori TAKANO \\ Analysis Center, Nomura Micro Science Co., Ltd., 2-2-19, Okada, Atsugi, Kanagawa, 243-0021, Japan
}

(Manuscript submitted February 27, 2003; accepted April 18, 2003)

\begin{abstract}
In this paper, we report on our research on the use of the ultraviolet (UV) oxidation method to remove total organic carbon (TOC), while focusing on the phenomenon that dissolved oxygen (DO) increases at outlet of the column packed with ion exchange resins. In addition, we also researched the behavior of hydrogen peroxide that is said to be in an equilibrium state with $\mathrm{OH}$ (hydroxy) radical. As a result, it was found that hydrogen peroxide is decomposed/deoxidized in the ion exchange column, which leads to a DO increase at outlet of the column.
\end{abstract}

\section{Introduction}

Ultrapure water used in the semiconductor or liquid crystal manufacturing process contains control items such as metals, silica, anion, particles, TOC, DO, and resistivity. In particular, the ultrapure water quality required for semiconductor manufacturing is extremely strict, and the required DO concentration in ultrapure water used for the most advanced semiconductor manufacturing process is less than $3 \mathrm{mg} / \mathrm{m}^{3}$ (ppb: parts per billion). By using such high-grade ultrapure water, current ultra-large scale integrated circuits (ULSI) have been produced. In the ultrapure water production process, a variety of organic matters -including high molecular weight, low molecular weight, ionic, and nonionic substances -- are targeted for removal. The removal of TOC in the polishing system is done by employing the UV oxidation method, a water treatment method that irradiates water with UV in the UV oxidation system and then supplies it to the mixed bed ion exchange column. In the UV oxidation method, a DO increase occurs at outlet of the mixed bed ion exchange column, by which the DO concentration previously reduced to low levels in the make up system may increase again in the polishing system. Because isolating the cause of the DO increase could effectively improve ultrapure water quality, we performed different research projects. We also could have succeeded in clarifying the mechanism of the DO increase by understanding the behavior of hydrogen peroxide using a highly sensitive hydrogen peroxide analyzer that can measure a trace of hydrogen peroxide.

\section{Experimental Test}

To confirm that DO increases at outlet of the column using the UV oxidation method, the test line 
was prepared with the installation of the UV oxidation system and mixed bed ion exchange column at the terminal of outlet of the ultrapure water system. UV irradiation was done by the system using a low-pressure mercury lamp. This lamp is well-suited for TOC removal; also, the strength of $200 \mathrm{~nm}$ or less is strong and the strength near $185 \mathrm{~nm}$ is especially strong. In this test, the irradiation strength of $\mathrm{UV}$ is set at the ultrapure water of $1 \mathrm{~m}^{3}$ within $1.2 \mathrm{~kW}$. The ultrapure water supply quantity was set to fill the mixed bed ion exchange column with strong acidity cationic resin and strong base anion resin, and to have the space velocity reach 35 $\mathrm{h}^{-1}$.

Then, a sufficient rinsing of the UV oxidation system was done, without turning on its power. At the same time, TOC was measured at inlet of the UV oxidation system and outlet of the column, and DO was measured at inlet of the UV oxidation system and inlet/outlet of the column. Still, the TOC monitor used in this test was A-1000XP as made by ANATEL Co. of the UV oxidation method, which was suitable for the TOC measurement of the low concentration; the DO monitor used was MOCA-3600 as made by the Orbisphere Laboratory Co.

After confirming that TOC and DO at outlet of the column was stabilized, the UV oxidation system was turned on, and data of concentrations of TOC, DO, and hydrogen peroxide, etc. were then taken. The hydrogen peroxide monitor used in this test is NOXIA-L as made by NOMURA MICRO SCIENCE Co. (NMS). This monitor is a high sensitive monitor that uses the iodine electrode method, and it allows for the measurement of hydrogen peroxide at several ppb levels continuously.

\section{Results and Discussions}

Figure 1 shows a schematic diagram of the test line. For feed water to the test line, ultrapure water with the quality shown in Table 1 was used to prevent a secondary reaction or the interference of impurities mixed into water. Fig. 2 shows the measurement results of TOC and DO in the test line in Fig. 1. In Figure 2, the point of a sharp drop of DO value at inlet of the column indicates the point of time at which the UV oxidation system in the test line was turned on. By turning on the UV oxidation system, the TOC value at outlet of the column had decreased up to about $0.5 \mathrm{mg} / \mathrm{m}^{3}$ and had then stabilized. The DO value at inlet of the column had sharply decreased

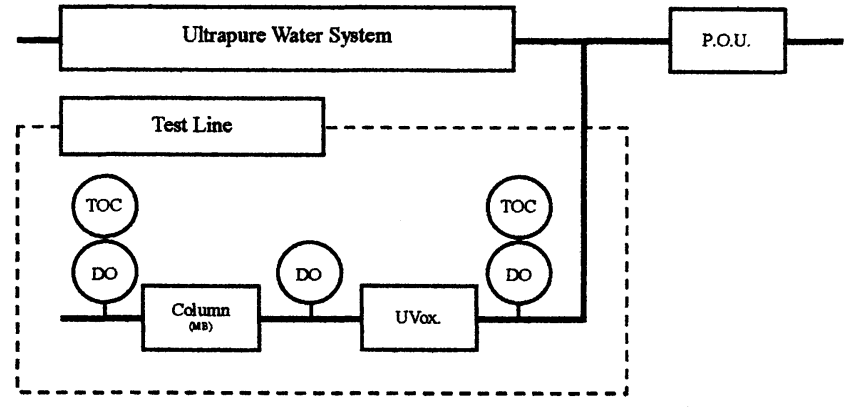

Fig. 1 Schematic diagram of test flow

Table 1 Ultrapure water quality

\begin{tabular}{|l|c|c|c|}
\hline \multirow{2}{*}{} & TOC & DO & Resistivity \\
\cline { 2 - 4 } & {$\left[\mathrm{mg} / \mathrm{m}^{3}\right]$} & {$\left[\mathrm{mg} / \mathrm{m}^{3}\right]$} & {$[\mathrm{M} \Omega \mathrm{cm}]$} \\
\hline U.P.W. & $\leqq 1$ & $2.0-2.5$ & 18.2 \\
\hline
\end{tabular}
up to about $0.2 \mathrm{mg} / \mathrm{m}^{3}$ and had then stabilized. The DO value at outlet of the column had temporarily decreased to almost the same value as that of inlet of the UV oxidation system. As operation time passed, however, the DO value had repeated fluctuations and then increased up to $4 \mathrm{mg} / \mathrm{m}^{3}$. On the other hand, the DO value indicated at inlet of the UV oxidation system had remained constant at around $2.3 \mathrm{mg} / \mathrm{m}^{3}$, and the DO value at inlet of the column had remained constant at around $0.2 \mathrm{mg} / \mathrm{m}^{3}$. From the above results, some other factor is believed present that could not be identified from the measurements of TOC and DO alone. When TOC is removed using the UV oxidation method, ultrapure water is also irradiated by UV with UV oxidation system. It is said that the $\mathrm{OH}$ radical generated irradiation can oxidize/ decompose TOC,[1-3] and 
it is also reported that hydrogen peroxide is generated as a by-product of $\mathrm{OH}$ radical.[1-3] At the same time, it is known that deterioration of ion exchange resins or ion exchange performance degradation is caused by an oxide such as hydrogen peroxide mixed into the ion exchange column,[4-5] which leads to the deterioration of treated water quality as shown in Fig. 3. Taking this information into consideration, we measured the hydrogen peroxide in the test line using a high sensitive hydrogen peroxide analyzer. Its measurement results are shown in Table 2 . Because hydrogen peroxide had increased after turning on the UV oxidation system, it was confirmed that hydrogen peroxide had been generated through UV irradiation to the water. Also, because hydrogen peroxide had decreased at outlet of the column, it is thought that hydrogen peroxide generated in the UV oxidation system had been decomposed/ deoxidized, which affected the DO concentration at outlet of the column.

At the outlet of UV oxidation system, DO decreased at $2 \mathrm{mg} / \mathrm{m}^{3}\left(0.06 \mu \mathrm{M}\left(\mathrm{M}=\mathrm{mol} / \mathrm{dm}^{3}\right)\right)$ and hydrogen peroxide increased at $8 \mathrm{mg} / \mathrm{m}^{3}(0.24$ $\mu \mathrm{M})$. Considering consuming oxygen also to oxidization of TOC, it is thought that oxygen required for generation of hydrogen peroxide is not necessarily supplied only from DO, and is

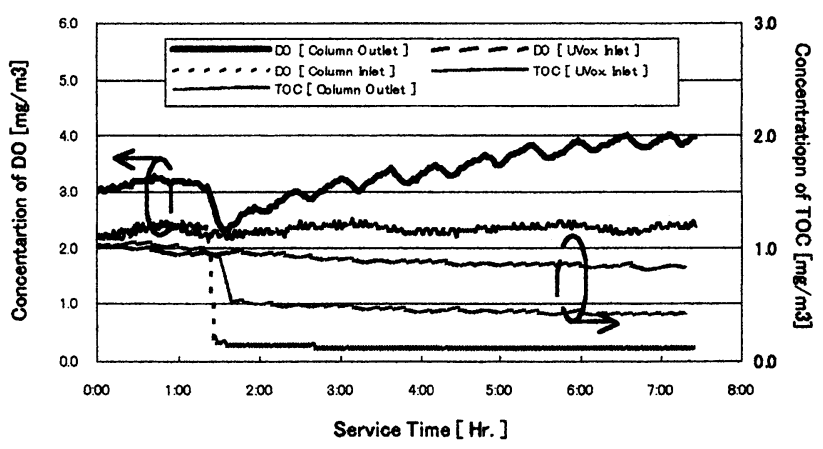

Fig. 2 Behavior of TOC and DO by the UV oxidation method

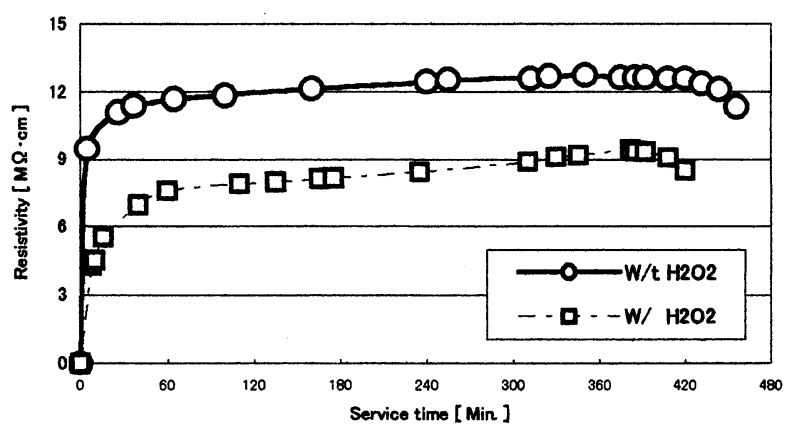

Fig. 3 Effect of the oxidizing agent of MB to characteristics

Table 2 Measurement result of hydrogen peroxide

\begin{tabular}{|c|c|c|c|}
\hline & $\begin{array}{c}\text { UVox. } \\
\text { Inlet }\end{array}$ & $\begin{array}{c}\text { UVox. } \\
\text { Outlet }\end{array}$ & $\begin{array}{c}\text { MB } \\
\text { Outlet }\end{array}$ \\
\cline { 2 - 4 }$\left[\mathbf{m g} / \mathbf{m}^{3}\right]$ & {$\left[\mathbf{m g} / \mathbf{m}^{\mathbf{s}}\right]$} & {$\left[\mathbf{m g} / \mathbf{m}^{3}\right]$} \\
\hline UV OFF & 8 & 7 & 1 \\
\hline UV On & 8 & 16 & 2 \\
\hline
\end{tabular}
supplied also from another factor. In this test, the ultrapure water of water quality shown in Table 1 is used, and the $\mathrm{OH}$ radical seems to be concerned in the generation of hydrogen peroxide, because the subsidiary reaction that is being generated is difficult to be considered. In the column outlet, $12 \mathrm{mg} / \mathrm{m}^{3}(0.35 \mu \mathrm{M})$ of hydrogen peroxide decreased, and $4 \mathrm{mg} / \mathrm{m}^{3}(0.13 \mu \mathrm{M})$ of DO increased. The amount of increase of the DO is $5.6 \mathrm{mg} / \mathrm{m}^{3}(0.18 \mu \mathrm{M})$, when $12 \mathrm{mg} / \mathrm{m}^{3}(0.35 \mu \mathrm{M})$ of hydrogen peroxide decomposed. A theoretical oxygen amount of increase as $12 \mathrm{mg} / \mathrm{m}^{3}(0.35 \mu \mathrm{M})$ hydrogen peroxide decomposed is $5.6 \mathrm{mg} / \mathrm{m}^{3}(0.18 \mu \mathrm{M})$, which is a little different from the measurement result. Also, it was considered that DO increases by the decomposition of hydrogen peroxide.

The mechanism of DO increase with the UV oxidation method, including the above results, is shown in Fig. 4. The first reaction is to generate $\mathrm{OH}$ radical through $\mathrm{UV}$ irradiation to the water. The second reaction is to oxidize/decompose TOC by $\mathrm{OH}$ radical/UV. TOC is decomposed into low molecular weight of organic acid and carbonic acid through the second reaction. The third reaction is to remove the oxidized/decomposed TOC using ion exchange resins. The fourth reaction is the equilibrium of $\mathrm{OH}$ radical and hydrogen peroxide, while the fifth reaction is to generate oxygen through decomposition/deoxidation of hydrogen peroxide in the 
column. The first to third reactions focus on TOC. The fourth and fifth reactions focus on $\mathrm{OH}$ radical/hydrogen peroxide, which are the reactions that directly contribute to $\mathrm{DO}$ increase.

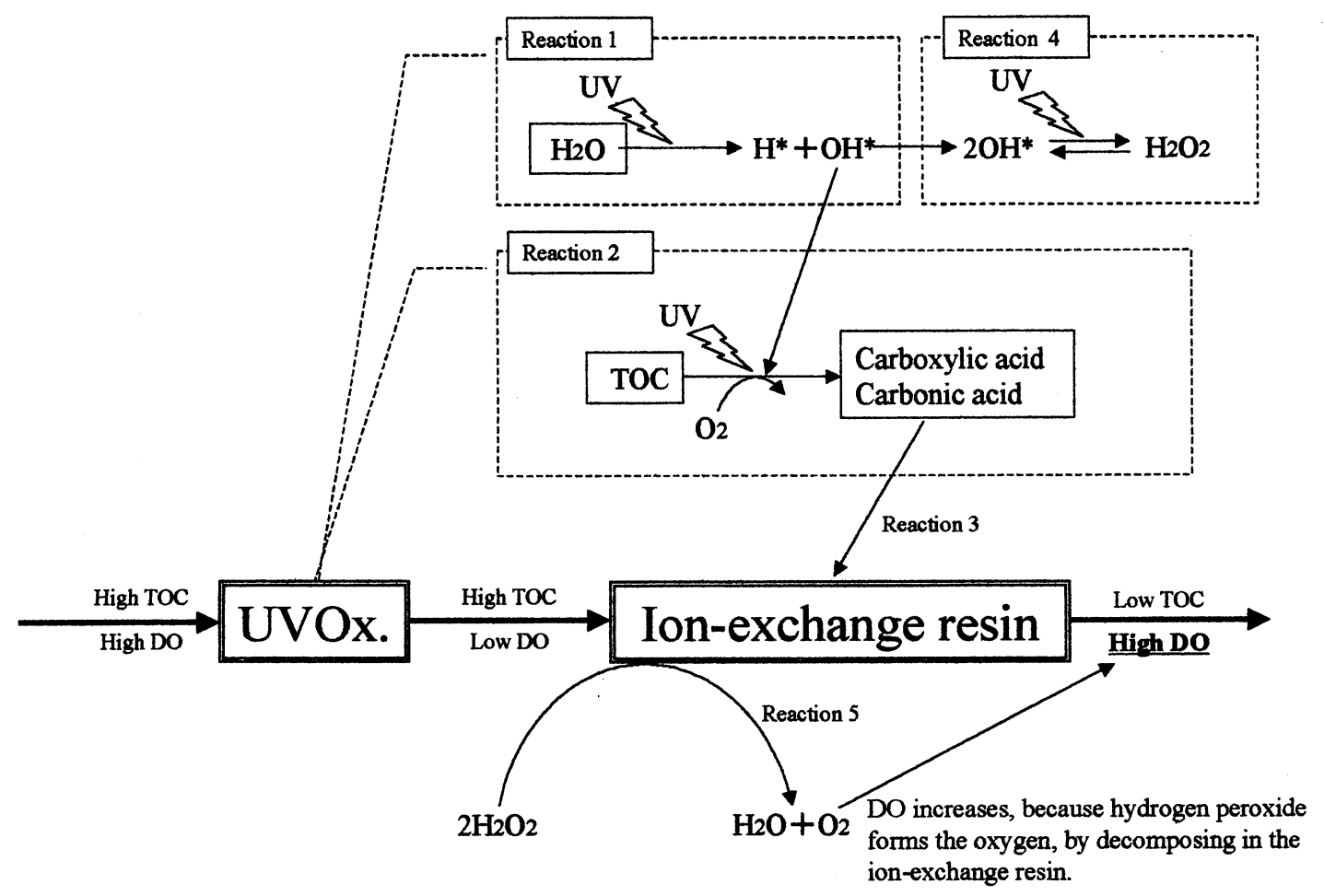

Fig. 4 DO increase mechanism

From these results, we concluded that the DO increase at the outlet of the column was due to a trace of $\mathrm{OH}$ radical/hydrogen peroxide generated through $\mathrm{UV}$ irradiation to the water. Because the existence of $\mathrm{OH}$ radical/hydrogen peroxide is the essential condition in the UV oxidation method, it is thought difficult to find measures to control the generation of those substances. However, ultrapure water quality can be expected to be improve by actively removing $\mathrm{OH}$ radical/hydrogen peroxide.

\section{References}

1) T. Ohmi, Science of Ultrapure Water, 370-375 (1990)

2) Dirk-M. Pfenning, J. Ultrapure Water, 17, 49-54 (2000)

3) Avijit Dey, Gareth Thomas, Kiran Arun Kekre, and Tao Gui He, J. Ultrapure Water, 20, 18-24 (2003)

4) Mitsubishi Chemical Corporation Separation Material Department, DIAION I , 14-67 (1995)

5) Mitsubishi Chemical Corporation Separation Material Department, DIAION II, 45-48 (1995) 